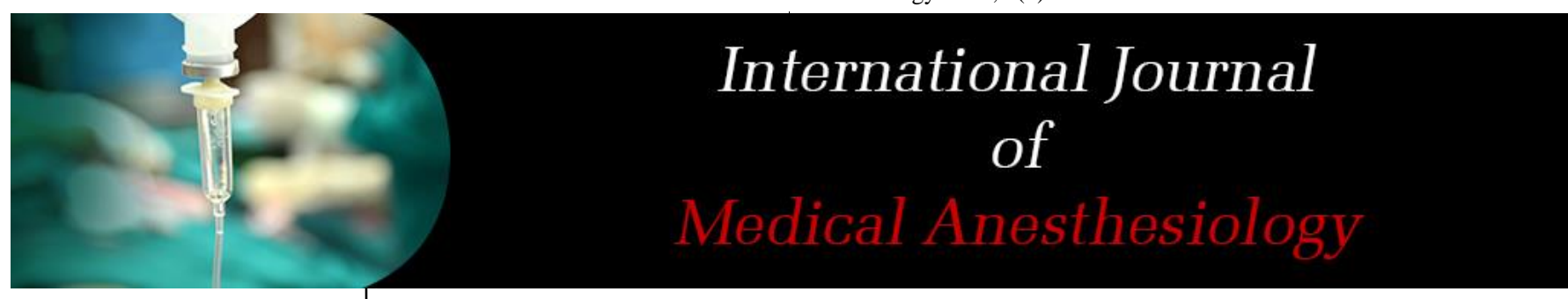

E-ISSN: 2664-3774

P-ISSN: 2664-3766 www.anesthesiologypaper.com IJMA 2019; 2(1): 03-05

Received: 05-04-2019

Accepted: 08-05-2019

Dr. Farha Fatima Assistant Professor, Department of Anaesthesia, Dr. VRK Women's Medical College, Aziz Nagar,

Hyderabad. Telangana, India

Dr. Syed Firasath Hussaini Assistant Professor, Department of Anaesthesia, Dr. VRK Women's Medical College, Aziz Nagar, Hyderabad. Telangana, India

Corresponding Author: Dr. Syed Firasath Hussaini Assistant Professor, Department of Anaesthesia, Dr. VRK Women's Medical College, Aziz Nagar,

Hyderabad. Telangana, India

\section{A comparative study on different doses of suxamethonium, rocuronium and vecuronium with respect to onset time action and side effects}

\author{
Dr. Farha Fatima and Dr. Syed Firasath Hussaini
}

DOI: https://doi.org/10.33545/26643766.2019.v2.i1a.17

\begin{abstract}
The ease with which endotracheal intubation is performed depends upon degree of muscle relaxation, depth of anaesthesia and skill of anaesthesiologist. This is prospective, randomised observational study conducted at Deccan academy of Medical Sciences and Research Centre, Hyderabad. The aim of this study is to compare the effect of suxamethonium, vecuronium and rocuronium on intubation time and intubating conditions when used along with rocuronium. 75 patients aged between 30 to 50 year of both genders, weighing from 40 to $70 \mathrm{~kg}$ coming for elective surgeries under general anaesthesia included. They are divided in three groups, Group 1received $0.6 \mathrm{mg} / \mathrm{kg}$ rocuronium, and Group II received Suxamethonium $1.5 \mathrm{mg} / \mathrm{kg}$. And group III vecuronium $0.1 \mathrm{mg} / \mathrm{kg}$. Intubating conditions were assessed by cooper scoring system. In Group I, 15patients showed excellent, 10 patients good and no patients showed poor intubation conditions and in group II all patients (25) showed excellent, and group III all patients showed good intubation conditions respectively. The onset time of intubating condition of three groups were 82.95 \pm 20.34 in Group I compared with $60.25 \pm 9.41$ in Group II whereas in group III 154.5 \pm 6.47 . These timings were significantly reduced in Group II compared to Group I and Group III. Vecuronium $0.1 \mathrm{mg} / \mathrm{kg}$ produces good intubation conditions at $60 \mathrm{sec}$ when compared with Vecuronium $0.8 \mathrm{mg} / \mathrm{kg}$ provides excellent intubating conditions within 60-66 secs without any adverse effects in elective surgeries in patients with stable haemodynamics.
\end{abstract}

Keywords: Intubation, vecuronium, rocuronium, cooper score

\section{Introduction}

A perfect setting for tracheal intubation include a rapid onset, profound paralysis of all muscles and short duration of action so that the patient's own respiratory function can be restored. These requirements are best met by succinylcholine, an ultra-short acting depolarizing muscle relaxant. However its many unwanted side effects have necessitated a search for an alternative drug or technique to facilitate tracheal intubation. Rocuronium bromide is a steroid, non-depolarizing neuromuscular blocking agent with a rapid onset and an intermediate duration of action. It may be a suitable alternative to succinylcholine ${ }^{[1]}$.

Succinylcholine (also known as suxamethonium chloride - introduced by Thesleff and Foldes in 1952) with its ultra-rapid onset and short duration of action has been drug of choice to obtain excellent intubating conditions in less than $60 \mathrm{~s}$ for both elective and emergency surgeries. However, the undesired side effects of succinylcholine led to a search for ideal neuromuscular blocking agent among the no depolarizing type. Rocuronium bromide introduced into clinical practice by Dr. Sleigh and late Dr. Savage in 1990 was the first drug to challenge the onset time of succinylcholine facilitating rapid and safe ET intubation devoid of its side effects.

In this context, the present study was undertaken to compare the intubating conditions of rocuronium, vecuronium with that of succinylcholine along with the clinical duration of action, the hemodynamic changes, and the occurrence of any untoward side effects with either drug.

\section{Aim of Study}

To study and compare the efficacy of Suxamethonium, Rocuronium and Vecuronium in patients with respect to:

1. Intubating conditions at one minute

2. Adverse effects 


\section{Materials and Methods \\ Study Design}

The proposed study entitled Intubating conditions with the use of suxamethonium chloride, vecuronium bromide and rocuronium bromide in paediatric patients

\section{Type of study}

A comparative observational study

\section{Place of study}

The study was carried out in the Department of Anaesthesiology, Princes Esra Hospital, Deccan college of Medical Science.

\section{Study Population}

75 patients of either sex aged between 1 to 9 years of ASA grade 1/II, scheduled to undergo various surgical procedures were chosen as subjects of this study with informed consent.

\section{Inclusion criteria}

Pre anaesthetic assessment of each patient was done by taking a detailed history along with a careful and complete general examination one day prior and again on the morning of surgery.

\section{Exclusion criteria}

Rule out the presence of any undetected systemic disorders such as haematological and biochemical profile, as well as routine urological investigations etc.

\section{Study Design}

The proposed study entitled intubating conditions with the use of suxamethonium chloride, vecuronium bromide and rocuronium bromide in paediatric patients.

After ensuring a fasting status of minimum four hours, the patients were premeditated with midazolam $0.5 \mathrm{mg} / \mathrm{kg}$ oral. Grouping was done into three lots of 25 each, and patients were randomly allocated to any one of the following

Group I: Intubation accomplished with IV Rocuronium 0.6 $\mathrm{mg} / \mathrm{kg}$.

Group II: Intubation accomplished with IV Suxamethonium $1.5 \mathrm{mg} / \mathrm{kg}$.

Group III: Intubation accomplished with IV Vecuronium $0.1 \mathrm{mg} / \mathrm{kg}$.

\section{Cooper scoring system}

Scoring of intubating conditions based on four criteria's was used to rate the degree of relaxation achieved in the three groups.

\begin{tabular}{|c|c|c|c|}
\hline \multirow{2}{*}{ Criteria } & \multicolumn{3}{|c|}{ Score } \\
\cline { 2 - 4 } & $\mathbf{1}$ & $\mathbf{2}$ & $\mathbf{3}$ \\
\hline Jaw relaxation (Ease of laryngoscopy) & Minimal (Impossible) & Moderate (Difficult) & Complete (easy) \\
\hline Vocal cords & closed & Intermediate & abducted \\
\hline Diaphragmatic & Coughing & Bucking & None \\
\hline Limb movement & Vigorous & Slight & None \\
\hline
\end{tabular}

Total score:

12: Excellent

8-11: Good

4-7: Poor

Anaesthetic technique: An intravenous route was secured upon the patient's arrival in the operation theatre and Inj Atropine $0.01 \mathrm{mg} / \mathrm{kg} \mathrm{I.V}$ was administered. Monitoring equipment was then attached and pre induction heart rate, pulse oximetry and non-invasive blood pressure reading were taken.

The ulnar nerve at wrist was selected for neuromuscular monitoring, using surface (ball) electrodes attached to the Organon Teknika neuromuscular monitor. A base line single twitch response was noted.

Preoxygenation was done for five minutes on $100 \%$ oxygen. Patients were induced using Thiopentone sodium $5 \mathrm{mg} / \mathrm{kg}$ body weight followed by the muscle relaxant preselected for study.

Assessment of quality of intubating conditions was performed using a scoring system based on 4 criteria's i.e. jaw relaxation, vocal cord position, diaphragmatic response and limb movement.

Laryngoscopy was first attempted at $60 \mathrm{sec}$. In case laryngoscopy was not possible attempts were repeated at subsequent intervals of $30 \mathrm{sec}$ up to $150 \mathrm{sec}$, when intubation was to be considered as a failure for the purpose of study.
Neuromuscular monitor was used to observe the correlation between the intubating conditions and the adductor pollicis response to single twitch ulnar nerve stimulation.

Following the intubation IV pethidine $1 \mathrm{mg} / \mathrm{kg}$ body weight and IV Ondansterone $0.1 \mathrm{mg} / \mathrm{kg}$ b.w were administered. Anaesthesia was maintained on mixture with controlled ventilation using the Boyle's anaesthesia machine. Muscle relaxation was maintained as necessary, using $1 / 4$ initial dose of relaxant administered. The patients in Gp II (I.E Intubation using suxamethonium $1.5 \mathrm{mg} / \mathrm{kg}$ ) were subsequently administered IV vecuronium as necessary.

\section{Parameters monitored}

Haemodynamic parameters, heart rate, pulse oximetry, noninvasive blood pressure (Systolic, diastolic, mean).

Neuromuscular monitoring was accomplished using the Organon Teknika and the response to single twitch nerve stimulation was virtually assessed.

Onset of action of intubating dose of the muscle relaxant was taken as the time from administration of drug to the time of intubation $\mathrm{n}$ with good to excellent intubating condition as per the scoring system based on 4 criteria.

At the end of surgical procedure, spontaneous recovery was attempted. Reversal of residual neuromuscular block was carried out. If necessary using IV atropine $0.02 \mathrm{mg} / \mathrm{kg}$ and neostigmine $0.05 \mathrm{mg} / \mathrm{kg}$. Patient was extubated after adequate Oropharyngeal toilet. 


\section{Results}

Table 1: Total scoring of Intubation conditions in the three groups

\begin{tabular}{|c|c|c|c|c|c|c|c|c|c|c|c|c|c|}
\hline \multirow{3}{*}{ Total score } & \multirow{3}{*}{ Score } & \multicolumn{4}{|c|}{ Group I } & \multicolumn{3}{|c|}{ Group II } & \multicolumn{5}{|c|}{ Group III } \\
\hline & & \multicolumn{12}{|c|}{ Time in seconds } \\
\hline & & 60 & 90 & 120 & 150 & 60 & 90 & 120 & 150 & 60 & 90 & 120 & 150 \\
\hline Excellent & 1 & - & - & - & - & - & - & - & - & - & - & - & - \\
\hline Good & 2 & 5 & - & - & - & - & - & - & - & -- & - & 12 & 08 \\
\hline Poor & 3 & 20 & - & - & - & 25 & - & - & - & - & - & 3 & 2 \\
\hline
\end{tabular}

The above table depicts the distribution of total scoring in the three groups. An excellent score seen in all cases of Group II within 60 sec. In Group I 60\% had excellent and $40 \%$ had good intubation condition within $60 \mathrm{sec}$. All the patients in group III had only good intubating conditions that were achieved at $120 \mathrm{sec}$ in $60 \%$ and at $10 \mathrm{sec}$ in $40 \%$ of the patients.

Table 2: Incidence of Grades of intubating conditions

\begin{tabular}{|c|c|c|c|c|c|c|c|}
\hline \multirow{2}{*}{ Grade } & \multirow{2}{*}{ Score } & \multicolumn{2}{|c|}{ Group I } & \multicolumn{2}{c|}{ Group II } & \multicolumn{2}{c|}{ Group III } \\
\cline { 3 - 8 } & & No & \% & No & \% & No & \% \\
\hline Excellent & 12 & 15 & 60 & 25 & 100 & - & - \\
\hline Good & $8-11$ & 10 & 40 & - & - & 25 & 100 \\
\hline Poor & $4-7$ & - & - & - & - & - & - \\
\hline
\end{tabular}

The above tables shows the grades of intubating conditions

in the three groups

Table 3: Onset time of intubating doses in the three groups

\begin{tabular}{|c|c|c|c|}
\hline \multirow{2}{*}{ Intubating dose of Drugs (mg/kg b w) } & Group I & Group II & Group III \\
\cline { 2 - 4 } & (Rocu 0.6 mg/kg b. w) & (Suxamet 1.5mg/kg b. w) & (Vecuro 0.1 mg/kg b. w) \\
\hline Onset of time (In Sec) & $82.95 \pm 20.34$ & $60.25 \pm 9.41$ & $154.5 \pm 6.47$ \\
\hline
\end{tabular}

The above table depicts the Onset time of intubating dose in the three groups (mean $\pm \mathrm{SD}$ ).

\section{Discussion}

Muscle relaxation is used to serve two purposes: one to facilitate endotracheal intubation and other to provide surgical relaxation ${ }^{[1]}$. The ideal neuromuscular blocking agent is one which has brief duration of action, provides profound relaxation and is free from haemodynamic changes. Rocuronium reliably produces muscle relaxation within 60 seconds of its administration with fewer side effects. Rocuronium is amino steroid no depolarizing muscle relaxant with rapid onset and intermediate duration of action. It has a faster neuromuscular blockade onset time compared to other NDMRs ${ }^{[3]}$.

Intubating conditions were graded as excellent when intubating scores were between 8 and 9, good with 6-7, fair with 3-5 and poor with 0-2. Excellent and good intubating conditions were considered clinically acceptable as per Cooper et al. ${ }^{[2]}$. Data noted included loss of thumb adduction, onset time of intubation, conditions at the time of intubation (Using Cooper's scoring system), heart rate, mean arterial pressure, oxygen saturation (using pulse oximetry) at baseline, post-induction, at intubation, immediately after intubation, $1 \mathrm{~min}, 3 \mathrm{~min}$ and $5 \mathrm{~min}$ after intubation. Various haemodynamic parameters like heart rate, systolic blood pressure, diastolic blood pressure and mean arterial pressure were evaluated. All these parameters increased following laryngoscopy and intubation ${ }^{[4]}$. The increase was maximum at 1 minute after intubation. All the parameters decreased thereafter towards resting values in all the three groups. These changes were not statistically significant.

\section{Untoward side effects}

In the present study, no adverse effects were found with either $0.6 \mathrm{mg} / \mathrm{kg} \mathrm{b}$. w of vecuronium and rocuronium who were given Suxamethonium $1 \mathrm{mg} / \mathrm{kg}$ b. w which are similar to the studies done by other authors.

\section{Conclusion}

We conclude that Rocuronium is a suitable alternative to Succinylcholine for intubation in paediatric patients in a dose of $0.9 \mathrm{mg} / \mathrm{kg}$ or $1.2 \mathrm{mg} / \mathrm{kg}$. The dosing of Rocuronium can be fixed depending on the duration of surgery owing to slight difference in duration of action of the two doses.

\section{Acknowledgement}

The author thankful to Hospital management to provide all the facilities to carry out this research work.

\section{Conflict of interest}

There is no conflict of interest

\section{References}

1. Misra MN, Agarwal M, Pandey RP, Gupta A. A comparative study of rocuronium, vecuronium and succinylcholine for rapid sequence induction of anaesthesia. Ind J Anaesth. 2005; 49(6):469-473.

2. Cooper R, Mirakhur RK, Clarke RS, Boules Z. Comparison of intubating conditions after administration of Org 9246 (Rocuronium) and suxamethonium. Br J Anaesth 1992; 69:269-73.

3. Rao MH, Venkatraman A, Mallleswari R. Comparison of intubating conditions between rocuronium with priming and without priming: Randomized and doubleblind study. Indian J Anaesth. 2011; 55:494-8.

4. Magorian T, Flannery KB, Miller RD. Comparisonof rocuronium, succinylcholine, and vecuroniumfor rapidsequence induction of anesthesia in adult patients. Anaesthesiology. 1993; 79(5):913-8. 